\title{
Strut and tie models for analysis/design of external beam-column joints
}

\author{
R. L. Vollum* and J. B. Newman*
}

Imperial College

\begin{abstract}
Strut and tie models have been developed for external beam-column joints with and without joint stirrups. The modelling is fraught with difficulties that include determining forces at joint boundaries and strut dimensions. In view of these difficulties, it was found necessary to define strut widths empirically. Test data were used to show that stirrups can increase joint shear strength by less than their yield capacity. The model accounts for this by using a stiffness analysis to determine the proportion of joint shear force resisted by the stirrups at failure. The resulting model predicts joint shear strength more realistically than existing non-finite-element methods and some finiteelement techniques. It is necessarily complex but capable of incorporation in spreadsheet-based design techniques. The authors believe that the behaviour of beam-column joints is too complex to be modelled realistically with simple strut and tie models. If a simple design method is required, the authors recommend their simplified empirical method.
\end{abstract}

\section{Notation}

$A_{\text {sj }} \quad$ effective area of joint stirrups

$b_{\mathrm{c}}, b_{\mathrm{b}} \quad$ member width (c, column; $\mathrm{b}$, beam)

$b_{\mathrm{e}} \quad$ effective joint width

C constant defining width of direct strut in stiffness analysis

$C_{\mathrm{ce}}, C_{\mathrm{ci}} \quad$ concrete force in column at joint boundary (e, external column face; i, internal column face)

$C_{\mathrm{se}}, C_{\mathrm{si}} \quad$ compressive force in column bars assuming plane sections remain plane (e, external column face; i, internal column face; ${ }^{*}$, actual or adjusted force)

$D \quad$ strength of direct strut in beam-column joint

$d \quad$ effective depth (c, column)

$d^{\prime} \quad$ distance to centroid of reinforcement from adjacent concrete face

$e_{\mathrm{b}}, e_{\mathrm{t}} \quad$ eccentricity of $F_{\mathrm{v}}$ at bottom node and top node, respectively

$e_{\mathrm{db}}, e_{\mathrm{dt}} \quad$ eccentricity of $F_{\mathrm{vd}}$ at bottom node and top node, respectively

$e_{\mathrm{b}}^{\prime} \quad$ eccentricity of $F_{\mathrm{v}}-F_{\mathrm{vit}}$ at bottom node

$e_{\mathrm{ib}}, e_{\mathrm{it}} \quad$ eccentricity of $F_{\mathrm{vib}}, F_{\mathrm{vit}}$ at nodes

$F_{\mathrm{v}} \quad$ resultant vertical joint shear force

$F_{\text {vib }}, F_{\text {vit }}$ vertical component of force resisted by lower and upper indirect struts, respectively

$f \quad$ strain-softened concrete strength (d, direct strut; ib, lower indirect strut; it, upper indirect strut)

$f_{\mathrm{c}}^{\prime} \quad$ concrete cylinder strength

$f_{\mathrm{y}} \quad$ stirrup yield strength

$f_{\mathrm{yb}} \quad$ yield strength of beam flexural reinforce-

$h_{\mathrm{b}}, h_{\mathrm{c}} \quad \begin{aligned} & \text { ment } \\ & \text { member depth (b, beam; c, column) }\end{aligned}$

$K \quad$ multiplication factor for $T_{\mathrm{si}}$

$N, N_{\text {crit }}$ column load (crit, column load at which predicted joint strength is maximum)

$P \quad$ beam load (pred, predicted failure load; test, actual failure load)

SI stirrup index (min, stirrup index at which predicted strength with stirrups $=$ predicted strength without stirrups) (a different model is used for each analysis)

* Department of Civil and Environmental Engineering, Imperial College of Science, Technology and Medicine, Imperial College Road, London SW7 2BU, UK.

$T_{\text {se }}, T_{\mathrm{si}} \quad$ tensile force in column bars assuming plane sections remain plane $\left(^{*}\right.$, actual or adjusted force)

(MCR 779) Paper received 19 April 1999; last revised 30 June 1999; accepted 28 July 1999 
w strut width normal to its centre line (d, direct; $i$, indirect; $t$, top node; $b$, bottom node; ${ }^{*}$, effective width used in stiffness analysis)

$x$ depth of compressive stress block at joint boundary ( $t$, top node in column; $b$, bottom node in column)

$Y \quad$ position of centroid of effective joint stirrups below centre line of beam tensile reinforcement

$\alpha, \beta \quad$ efficiency factors

$\varepsilon_{1}, \varepsilon_{2} \quad$ principal strains

$\varepsilon_{\mathrm{c}}^{\prime} \quad$ strain at peak concrete stress

$\varepsilon_{\mathrm{d}} \quad$ axial strain in direct strut

$\varepsilon_{\mathrm{t}} \quad$ stirrup strain

$\theta \quad$ angle of centre line of top indirect strut to horizontal

$\rho_{\mathrm{b}} \quad$ beam reinforcement index $A_{\mathrm{s}} / b_{\mathrm{b}} d$

$\sigma^{*} \quad$ resultant stress in column at junction with node

$\phi_{\mathrm{b}}, \phi_{\mathrm{t}} \quad$ angle of centre line of indirect strut to horizontal (b, bottom; t, top)

\section{Introduction}

Strut and tie modelling is widely advocated ${ }^{1-6}$ as an alternative to either finite-element modelling or empirical methods for the design of structures such as deep beams, corbels, squat shear walls and beam-column joints. It is relatively straightforward to develop strut and tie models if the node dimensions can be related to the widths of supports and positions of reinforcement (e.g. deep beams). This is not the case for beamcolumn joints (see Fig. 1), where node dimensions are not easily defined. This can be seen by considering the

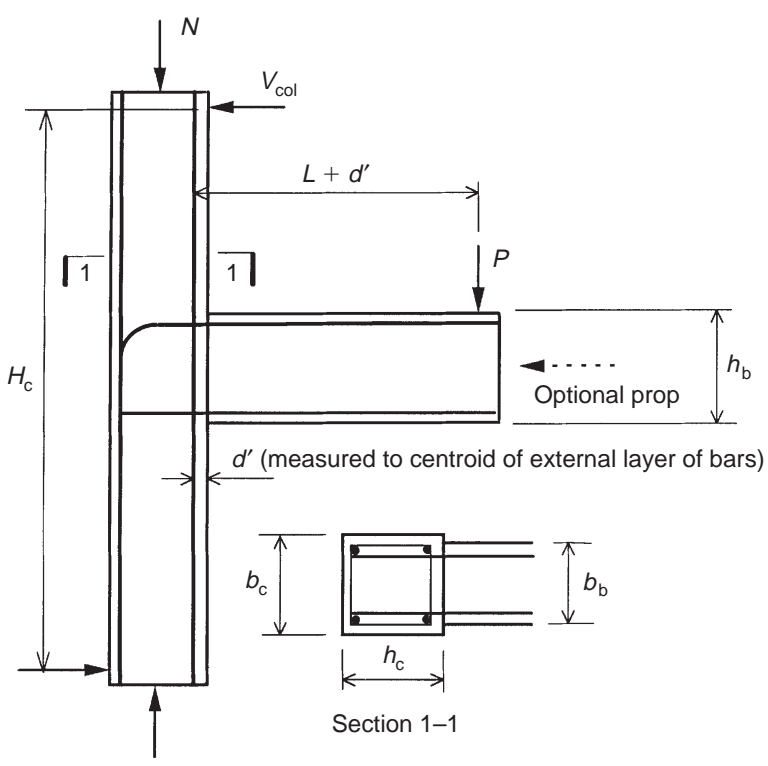

Fig. 1. External beam-column joint development of the strut and tie model shown in Fig. 2, which is summarized below:

(a) determine forces in the reinforcement and concrete at the joint boundaries

(b) determine the centre line of the inclined strut in terms of the positions of the centroids of the resultant forces at the joint boundaries

(c) determine node dimensions

(d) determine failure load in terms of the strength of the inclined strut.

Stages $(a)$ and $(c)$ present difficulties. The first difficulty is that the column bar forces are not readily established at the joint boundaries, because plane sec-

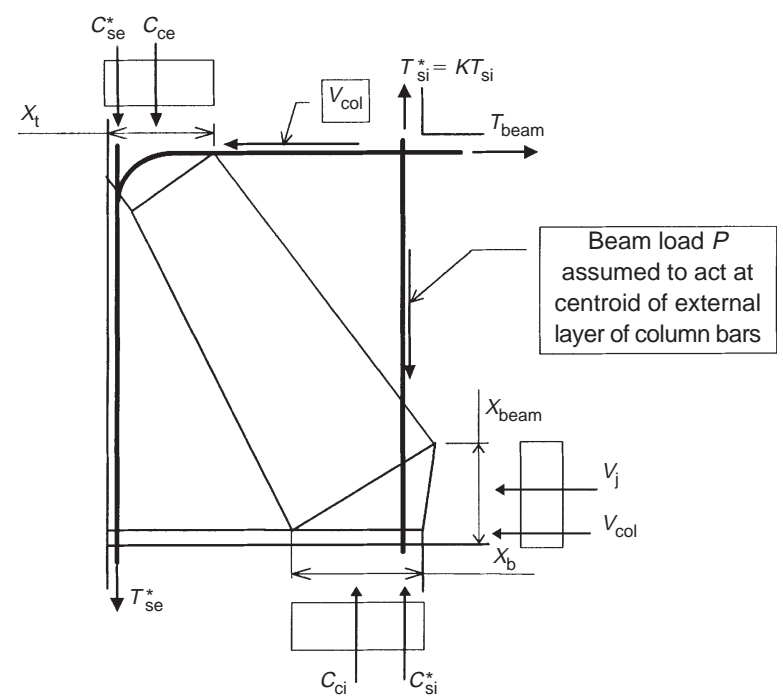

(a)

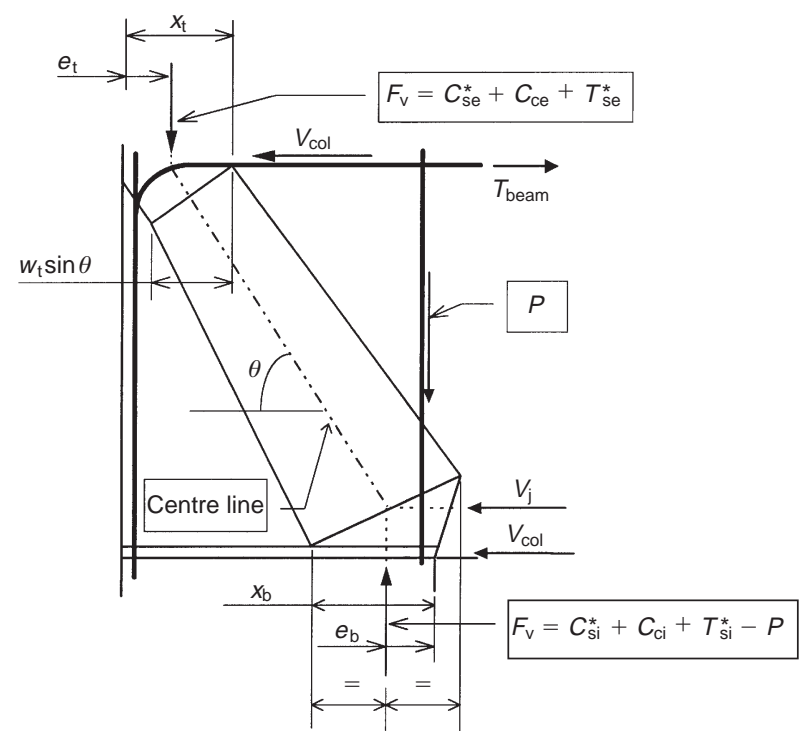

(b)

Fig. 2. Strut and tie model of beam-column joint without stirrups: (a) boundary forces; (b) geometry

Magazine of Concrete Research, 1999, 51, No. 6 
tions do not remain plane. The first author ${ }^{5}$ has established this by comparing column bar forces predicted assuming plane sections remain plane with forces derived from strains measured by Ortiz $^{6}$ and Scott. ${ }^{7}$ In most cases, the column bar forces were more tensile than predicted at the joint boundaries. The greatest differences between the predicted and measured forces were found at the top of the joint, where the tensile force in the inner column bars $T_{\mathrm{si}}^{*}$ was considerably greater than the predicted value $T_{\mathrm{si}}$ and the compressive force in the external column bars $C_{\mathrm{se}}^{*}$ was significantly less than predicted value $C_{\text {se }}$, even zero. This seems reasonable since bond conditions are more severe for the external column bars than for the internal column bars. Therefore, $T_{\mathrm{si}}^{*} / T_{\mathrm{si}}$ increases to maintain moment equilibrium as $C_{\mathrm{se}}^{*} / C_{\mathrm{se}}$ reduces owing to loss of bond towards failure. Stage $(c)$ presents difficulties because neither the height nor the width of a node is clearly defined. For example, the width of a node is dependent on the widths of the concrete stress blocks in the upper and lower columns, which in turn depend on the forces in the column bars, which are unknown. To complicate matters further, the stress distribution in the struts is non-uniform because force is introduced into the nodes from the main column reinforcement in addition to compression in the concrete. Furthermore, strain measurements in column bars within beamcolumn joints ${ }^{6,7}$ indicate that force is transferred between the steel and concrete throughout the depth of the joint rather than at nodes as assumed. In view of all this complexity, the authors do not consider it feasible to develop a realistic strut and tie model for beamcolumn joints without recourse to test data. Therefore, the authors have used a semi-empirical approach to develop an essentially descriptive strut and tie model for joints with and without stirrups.

\section{Strut and tie model for beam-column joint without stirrups}

A previous analysis ${ }^{5,8}$ of all known test data ${ }^{6,7,9-17}$ showed that joint shear strength

(a) is sensibly independent of column axial load unless a hinge forms in the upper column

(b) is proportional to $\sqrt{ } f_{\mathrm{c}}^{\prime}$ for joints without stirrups

(c) reduces with increasing joint aspect ratio $h_{\mathrm{b}} / h_{\mathrm{c}}$. Test data are limited (see Fig. 3) but there is some evidence ${ }^{8}$ that joint shear strength reduces by about $35 \%$, almost linearly, as $h_{\mathrm{b}} / h_{\mathrm{c}}$ is increased from 1 to 2 . (Recent tests by Scott and Hamil confirm that joint shear strength reduces with increasing $h_{\mathrm{b}} / h_{\mathrm{c}}$ (personal communication, 1999)).

The strut and tie model shown in Fig. 2 was calibrated to predict that joint shear strength varies as described above by choosing appropriate functions for the concrete strength $f_{\mathrm{d}}$ and strut width $w_{\mathrm{t}}$. Full details of the model are given elsewhere ${ }^{5}$ and only key details are described here. The strain-softening model of Collins et al. ${ }^{1}$ is used to calculate the concrete strength in the joint. The strain-softened concrete strength is

$$
f=\frac{f_{\mathrm{c}}}{0 \cdot 8+170 \varepsilon_{1}}<f_{\mathrm{c}}^{\prime}
$$

where $\varepsilon_{1}$ is the principal tensile strain. Equation (1) is based on the assumption that the maximum compressive stress is reached at a strain $\varepsilon_{\mathrm{c}}^{\prime}$ of -0.002 . If the compressive strain in the inclined strut is -0.002 at failure, a Mohr circle shows that the principal tensile strain $\varepsilon_{1}$ is given by

$$
\varepsilon_{1}=\varepsilon_{\mathrm{t}}+\left(\varepsilon_{\mathrm{t}}+0 \cdot 002\right) \cot ^{2} \theta
$$

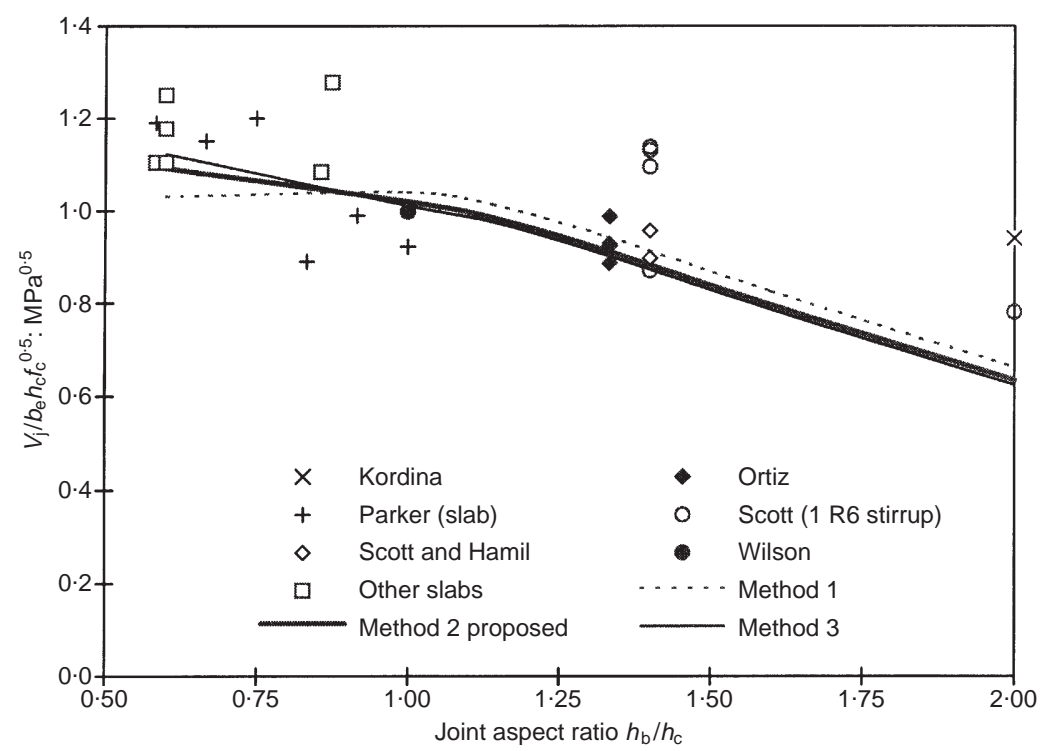

Fig. 3. Influence of aspect ratio on the joint shear strength of beam-column joints 
where $\theta$ is the angle between the directions of the principal compressive stress and the transverse (stirrup) strain $\varepsilon_{\mathrm{t}}$. The concrete compressive stress is given by

$$
\sigma=\left[2\left(\varepsilon_{2} / \varepsilon_{\mathrm{c}}^{\prime}\right)-\left(\varepsilon_{2} / \varepsilon_{\mathrm{c}}^{\prime}\right)^{2}\right] f
$$

where $\varepsilon_{2}$ is the principal compressive strain. Tests 6,7,9-13 show that joint shear strength can be significantly increased by the provision of joint stirrups but is much less dependent on the strain in the main column and beam reinforcement. This indicates that the concrete strength in the strut is principally related to stirrup strain and that $\varepsilon_{1}$ should be taken as the mean stirrup strain. This approach is not valid if joint stirrups are not provided. In the case of joints without stirrups, $\varepsilon_{\mathrm{t}}$ is assumed to be 0.003 at failure (corresponding to a typical yield strain of high-yield reinforcement) and equation (1) is modified as follows to make the predicted joint shear strength proportional to $\sqrt{ } f_{\mathrm{c}}^{\prime}$ as observed:

$$
f=\frac{5.92 f_{\mathrm{c}}^{\prime 0.5}}{0.8+170 \varepsilon_{1}}<f_{\mathrm{c}}^{\prime}
$$

The forces acting at the joint boundaries are shown in Fig. 2. The centre line of the strut is defined by the intersection of the lines of action of the horizontal and vertical joint shear forces at each node (see Fig. 2). The node dimensions are defined in terms of the widths of rectangular concrete stress blocks in the upper and lower columns, which in turn are related to the column bar forces. The width of the strut at the top node is taken as

$$
w_{\mathrm{t}}=2\left(x_{\mathrm{t}}-e_{\mathrm{t}}\right) \sin \theta
$$

where $x_{\mathrm{t}}$ is the width of the concrete stress block in the column at the top node and $e_{\mathrm{t}}$ is the eccentricity of the resultant vertical joint shear force $F_{\mathrm{v}}$ (see Fig. 2). Both $x_{\mathrm{t}}$ and $e_{\mathrm{t}}$ depend on the column bar forces and can be established from equilibrium. A similar definition of strut width is adopted for the bottom node.

It is assumed, on the basis of crack patterns at failure, ${ }^{5,6}$ that joint shear failure originates near the top node. Therefore, the joint shear strength is taken as

$$
V_{\mathrm{j}}=b_{\mathrm{e}} w_{\mathrm{t}} f_{\mathrm{d}} \cos \theta
$$

where $f_{\mathrm{d}}$ is the concrete strength in the strut and the effective joint width $b_{\mathrm{e}}$ is the lesser of $0 \cdot 5\left(b_{\mathrm{b}}+b_{\mathrm{c}}\right)$ and $b_{\mathrm{b}}+0 \cdot 5 h_{\mathrm{c}}$ if $b_{\mathrm{b}}<b_{\mathrm{c}}$, and the lesser of $b_{\mathrm{c}}+0.5 h_{\mathrm{c}}$ and $b_{\mathrm{b}}$ if $b_{\mathrm{b}}>b_{\mathrm{c}}$.

The following procedure is used to determine the failure load.

(a) Assume the column load to be zero.

(b) Calculate the forces in the concrete and reinforcement at the joint boundaries assuming plane sections remain plane (the rectangular-parabolic stress block of Eurocode $2^{18}$ is used with a maximum stress of $\left.0 \cdot 85 f_{\mathrm{c}}^{\prime}\left(1-f_{\mathrm{c}}^{\prime} / 250\right)\right)$.

(c) Multiply the tensile force $T_{\mathrm{si}}$ in the inner column bar by $K(>1)$ to account for redistribution. Make no adjustments to the forces in the other column bars or beam reinforcement. (The concrete stress block is modified to maintain equilibrium when the column bar forces are adjusted.)

(d) Establish the position of the centre line of the strut at the top and bottom nodes, the width of the stress blocks in the column, the strut width and, hence, the failure load.

The strut width was found by calibrating the model for the beam-column joint specimens of $\mathrm{Ortiz}^{6}$ without stirrups (see Table 1) by adjusting $K$ in step (c). Increasing $K$ increases the predicted failure load since it increases the strut width at the top node (see equation (6)) owing to the increase in width of the stress block in the upper column. The resulting strut width is

$$
w=0 \cdot 4 h_{\mathrm{c}} / \sin \theta
$$

where the function $h_{\mathrm{c}} / \sin \theta$ was chosen to make the predicted joint shear strength reduce with joint aspect ratio as observed. The strut width needs to be increased above $0.4 h_{\mathrm{c}} / \sin \theta$ to maintain a constant joint shear strength at column loads greater than zero. The proposed solution procedure avoids this problem by assuming that there is no load in the upper column. This is justified by the experimental observation that joint shear strength is sensibly independent of column load unless a hinge forms in the upper column. The analysis needs to be modified if the inner column bars yield in stage $(c)$ when $K$ is increased to increase the strut width to $0.4 h_{\mathrm{c}} / \sin \theta$. In this case, the column load is taken as the minimum of the actual column load and that at which the column bars yield when the strut width equals $0.4 h_{\mathrm{c}} / \sin \theta$. In the solution procedure, only the tensile force in the inner column bar is adjusted. In practice, the forces in all the column bars are more tensile than is predicted when assuming plane sections remain plane.

The sensitivity of the predicted failure load to variations in the column bar forces for a strut width of $0 \cdot 4 h_{\mathrm{c}} / \sin \theta$ was investigated ${ }^{5}$ and found to be small. This is demonstrated in Fig. 3, which shows the influence on the predicted failure load of adjusting the forces in the column bars (from forces calculated assuming plane sections remain plane) as follows.

(a) Method 1. Take strut width as $0 \cdot 4 h_{\mathrm{c}} / \sin \theta$ with no adjustment to column bar forces.

(b) Method 2. Increase the tensile force in the inner column bars to make the strut width $0.4 h_{\mathrm{c}} / \sin \theta$ at the top node.

(c) Method 3. Increase the tensile force in the inner and outer column bars to make the strut width $0 \cdot 4 h_{\mathrm{c}} / \sin \theta$ at the top and bottom nodes.

Method 2 was adopted because $(a)$ it is simple and $(b)$ it takes into account the observed tensile shift in the

Magazine of Concrete Research, 1999, 51, No. 6 


\begin{tabular}{|c|c|c|c|c|c|c|c|c|c|c|c|c|c|c|c|c|c|}
\hline Test & Test number & $H_{\mathrm{c}}: \mathrm{mm}$ & $L: \mathrm{mm}$ & $h_{\mathrm{c}}: \mathrm{mm}$ & $d_{\mathrm{c}}: \mathrm{mm}$ & $b_{\mathrm{c}}: \mathrm{mm}$ & $h_{\mathrm{b}}: \mathrm{mm}$ & $d_{\mathrm{b}}: \mathrm{mm}$ & $b_{\mathrm{b}}: \mathrm{mm}$ & $\rho_{\mathrm{b}}$ & $\begin{array}{l}f_{\mathrm{c}}^{\prime}: \\
\text { Mpa }\end{array}$ & $\begin{array}{l}f_{\mathrm{yb}}: \\
\mathrm{Mpa}\end{array}$ & $\begin{array}{c}A_{\mathrm{sje}} f_{\mathrm{y}} / b_{\mathrm{e}} h_{\mathrm{c}} f_{\mathrm{c}}^{0.5}: \\
\mathrm{Mpa}^{0.5}\end{array}$ & $N: \mathrm{kN}$ & $P: \mathrm{kN}$ & $\begin{array}{c}P / P_{\text {test }} \\
\text { strut and } \\
\text { tie }\end{array}$ & $\begin{array}{l}P / P_{\text {test }} \\
\text { Vollum }^{8} \\
\text { simple }^{8}\end{array}$ \\
\hline Ortiz $^{6}$ & $\begin{array}{l}\text { BCJ1 } \\
\text { BCJ2 } \\
\text { BCJ3 } \\
\text { BCJ4 } \\
\text { BCJ5 } \\
\text { BCJ6 } \\
\text { BCJ7 }\end{array}$ & $\begin{array}{l}2000 \\
2000 \\
2000 \\
2000 \\
2000 \\
2000 \\
2000\end{array}$ & $\begin{array}{l}1050 \\
1100 \\
1100 \\
1100 \\
1100 \\
1100 \\
1100\end{array}$ & $\begin{array}{l}300 \\
300 \\
300 \\
300 \\
300 \\
300 \\
300 \\
\end{array}$ & $\begin{array}{l}267 \\
267 \\
267 \\
267 \\
267 \\
267 \\
267\end{array}$ & $\begin{array}{l}200 \\
200 \\
200 \\
200 \\
200 \\
200 \\
200\end{array}$ & $\begin{array}{l}400 \\
400 \\
400 \\
400 \\
400 \\
400 \\
400 \\
\end{array}$ & $\begin{array}{l}367 \\
367 \\
367 \\
367 \\
367 \\
367 \\
367 \\
\end{array}$ & $\begin{array}{l}200 \\
200 \\
200 \\
200 \\
200 \\
200 \\
200 \\
\end{array}$ & $\begin{array}{l}0 \cdot 011 \\
0 \cdot 011 \\
0 \cdot 011 \\
0 \cdot 011 \\
0 \cdot 011 \\
0 \cdot 011 \\
0 \cdot 011\end{array}$ & $\begin{array}{l}34 \\
38 \\
33 \\
34 \\
38 \\
35 \\
35 \\
\end{array}$ & $\begin{array}{l}720 \\
720 \\
720 \\
720 \\
720 \\
720 \\
720 \\
\end{array}$ & $\begin{array}{l}0 \\
0 \cdot 16 \\
0 \\
0 \cdot 33 \\
0 \\
0 \\
0 \cdot 74 \\
\end{array}$ & $\begin{array}{r}0 \\
0 \\
0 \\
0 \\
300 \\
300 \\
300 \\
\end{array}$ & $\begin{array}{l}118 \\
125 \\
118 \\
130 \\
115 \\
115 \\
170 \\
\end{array}$ & $\begin{array}{l}1 \cdot 00 \\
0 \cdot 96 \\
0 \cdot 94 \\
1 \cdot 00 \\
1 \cdot 03 \\
0 \cdot 98 \\
1 \cdot 00\end{array}$ & $\begin{array}{l}0 \cdot 95 \\
0 \cdot 91 \\
0 \cdot 89 \\
0 \cdot 95 \\
0 \cdot 99 \\
0 \cdot 95 \\
1 \cdot 00\end{array}$ \\
\hline Kordina $^{13}$ & $\begin{array}{l}\text { RE2 } \\
\text { RE3 } \\
\text { RE4 } \\
\text { RE6 } \\
\text { RE7 }\end{array}$ & $\begin{array}{l}3000 \\
3000 \\
3000 \\
3000 \\
3000\end{array}$ & $\begin{array}{r}1000 \\
1000 \\
1000 \\
1000 \\
975\end{array}$ & $\begin{array}{l}200 \\
200 \\
200 \\
200 \\
250\end{array}$ & $\begin{array}{l}167 \\
167 \\
167 \\
167 \\
217\end{array}$ & $\begin{array}{l}200 \\
200 \\
200 \\
200 \\
230\end{array}$ & $\begin{array}{l}400 \\
300 \\
300 \\
300 \\
350\end{array}$ & $\begin{array}{l}365 \\
265 \\
265 \\
265 \\
315 \\
\end{array}$ & $\begin{array}{l}200 \\
200 \\
200 \\
200 \\
230\end{array}$ & $\begin{array}{l}0.009 \\
0.018 \\
0.012 \\
0.012 \\
0.013\end{array}$ & $\begin{array}{l}25 \\
40 \\
32 \\
32 \\
26 \\
\end{array}$ & $\begin{array}{l}420 \\
420 \\
420 \\
463 \\
448 \\
\end{array}$ & $\begin{array}{l}0 \\
0 \cdot 26 \\
0 \cdot 19 \\
0 \cdot 38 \\
0 \cdot 43\end{array}$ & $\begin{array}{r}240 \\
400 \\
51 \\
213 \\
650\end{array}$ & $\begin{array}{r}67 \\
80 \\
51 \\
66 \\
117\end{array}$ & $\begin{array}{l}0 \cdot 72 \\
0 \cdot 84 \\
0 \cdot 88 \\
0 \cdot 91 \\
0 \cdot 91\end{array}$ & $\begin{array}{l}0 \cdot 68 \\
0 \cdot 72 \\
0 \cdot 90 \\
0 \cdot 84 \\
0 \cdot 83\end{array}$ \\
\hline Taylor $^{11}$ & $\begin{array}{c}\mathrm{P} 1 / 41 / 24 \\
\mathrm{P} 2 / 41 / 24 \\
\mathrm{P} 2 / 41 / 24 \mathrm{~A} \\
\mathrm{~A} 3 / 41 / 24 \\
\mathrm{D} 3 / 41 / 24 \\
\mathrm{~B} 3 / 41 / 24\end{array}$ & $\begin{array}{l}1290 \\
1290 \\
1290 \\
1290 \\
1290 \\
1290\end{array}$ & $\begin{array}{l}470 \\
470 \\
470 \\
470 \\
470 \\
470\end{array}$ & $\begin{array}{l}140 \\
140 \\
140 \\
140 \\
140 \\
140\end{array}$ & $\begin{array}{l}110 \\
110 \\
110 \\
110 \\
110 \\
110\end{array}$ & $\begin{array}{l}140 \\
140 \\
140 \\
140 \\
140 \\
140\end{array}$ & $\begin{array}{l}200 \\
200 \\
200 \\
200 \\
200 \\
200\end{array}$ & $\begin{array}{l}170 \\
170 \\
170 \\
170 \\
170 \\
170\end{array}$ & $\begin{array}{l}100 \\
100 \\
100 \\
100 \\
100 \\
100\end{array}$ & $\begin{array}{l}0.024 \\
0.024 \\
0.024 \\
0.024 \\
0.024 \\
0.024\end{array}$ & $\begin{array}{l}33 \\
29 \\
47 \\
27 \\
53 \\
22\end{array}$ & $\begin{array}{l}500 \\
500 \\
500 \\
500 \\
500 \\
500\end{array}$ & $\begin{array}{l}0 \cdot 30 \\
0 \cdot 33 \\
0 \cdot 26 \\
0 \cdot 34 \\
0 \cdot 24 \\
0 \cdot 75\end{array}$ & $\begin{array}{r}240 \\
240 \\
240 \\
240 \\
60 \\
240\end{array}$ & $\begin{array}{l}35 \\
35 \\
47 \\
35 \\
50 \\
30\end{array}$ & $\begin{array}{l}1 \cdot 05 \\
0 \cdot 99 \\
0 \cdot 98 \\
0 \cdot 95 \\
0 \cdot 96 \\
1 \cdot 04\end{array}$ & $\begin{array}{l}0 \cdot 86 \\
0 \cdot 80 \\
0 \cdot 73 \\
0 \cdot 78 \\
0 \cdot 73 \\
1 \cdot 04\end{array}$ \\
\hline Scott $^{7}$ & $\begin{array}{c}\text { C1AL } \\
\text { C4 } \\
\text { C4A } \\
\text { C4AL } \\
\text { C7 }\end{array}$ & $\begin{array}{l}1700 \\
1700 \\
1700 \\
1700 \\
1700\end{array}$ & $\begin{array}{l}750 \\
750 \\
750 \\
750 \\
750\end{array}$ & $\begin{array}{l}150 \\
150 \\
150 \\
150 \\
150\end{array}$ & $\begin{array}{l}117 \\
117 \\
117 \\
117 \\
117\end{array}$ & $\begin{array}{l}150 \\
150 \\
150 \\
150 \\
150\end{array}$ & $\begin{array}{l}210 \\
210 \\
210 \\
210 \\
300\end{array}$ & $\begin{array}{l}179 \\
177 \\
177 \\
177 \\
267\end{array}$ & $\begin{array}{l}110 \\
110 \\
110 \\
110 \\
110\end{array}$ & $\begin{array}{l}0 \cdot 011 \\
0 \cdot 021 \\
0 \cdot 021 \\
0 \cdot 021 \\
0 \cdot 014\end{array}$ & $\begin{array}{l}33 \\
41 \\
44 \\
36 \\
35\end{array}$ & $\begin{array}{l}540 \\
540 \\
540 \\
540 \\
540\end{array}$ & $\begin{array}{l}0 \cdot 23 \\
0 \cdot 20 \\
0 \cdot 20 \\
0 \cdot 22 \\
0 \cdot 22\end{array}$ & $\begin{array}{r}50 \\
275 \\
275 \\
50 \\
275\end{array}$ & $\begin{array}{l}22 \\
30 \\
32 \\
28 \\
32\end{array}$ & $\begin{array}{l}1 \cdot 05 \\
0 \cdot 98 \\
0 \cdot 96 \\
0 \cdot 88 \\
1 \cdot 00\end{array}$ & $\begin{array}{l}1 \cdot 01 \\
0 \cdot 78 \\
0 \cdot 76 \\
0 \cdot 77 \\
0 \cdot 85\end{array}$ \\
\hline Scott and Hamil ${ }^{12}$ & $\begin{array}{l}\text { C4ALN0 } \\
\text { C4ALN1 } \\
\text { C4ALN3 } \\
\text { C4ALN5 } \\
\text { C4ALH0 }\end{array}$ & $\begin{array}{l}1700 \\
1700 \\
1700 \\
1700 \\
1700\end{array}$ & $\begin{array}{l}750 \\
750 \\
750 \\
750 \\
750\end{array}$ & $\begin{array}{l}150 \\
150 \\
150 \\
150 \\
150\end{array}$ & $\begin{array}{l}117 \\
117 \\
117 \\
117 \\
117\end{array}$ & $\begin{array}{l}150 \\
150 \\
150 \\
150 \\
150\end{array}$ & $\begin{array}{l}210 \\
210 \\
210 \\
210 \\
210\end{array}$ & $\begin{array}{l}177 \\
177 \\
177 \\
177 \\
177\end{array}$ & $\begin{array}{l}110 \\
110 \\
110 \\
110 \\
110\end{array}$ & $\begin{array}{l}0.021 \\
0.021 \\
0.021 \\
0.021 \\
0.021\end{array}$ & $\begin{array}{r}42 \\
46 \\
42 \\
50 \\
104\end{array}$ & $\begin{array}{l}522 \\
522 \\
522 \\
522 \\
522\end{array}$ & $\begin{array}{l}0 \\
0 \cdot 20 \\
0 \cdot 43 \\
0 \cdot 63 \\
0\end{array}$ & $\begin{array}{r}50 \\
50 \\
50 \\
50 \\
100\end{array}$ & $\begin{array}{l}27 \\
34 \\
35 \\
40 \\
43\end{array}$ & $\begin{array}{l}0 \cdot 89 \\
0.84 \\
0 \cdot 99 \\
0.99 \\
0.89\end{array}$ & $\begin{array}{l}0 \cdot 89 \\
0 \cdot 73 \\
0 \cdot 83 \\
0 \cdot 99 \\
0 \cdot 95\end{array}$ \\
\hline Wilson $^{14}$ & $\mathrm{~J} 1$ & 3000 & 850 & 300 & 269 & 154 & 300 & 257 & 154 & 0.017 & 32 & 520 & 0 & 450 & 76 & $1 \cdot 01$ & $1 \cdot 03$ \\
\hline $\begin{array}{l}\text { Parker and Bullman } \\
\text { (slab edge-column) }\end{array}$ & $\begin{array}{l}6 \mathrm{a} \\
6 \mathrm{~b} \\
6 \mathrm{c} \\
6 \mathrm{~d} \\
6 \mathrm{e} \\
6 \mathrm{f}\end{array}$ & $\begin{array}{l}2000 \\
2000 \\
2000 \\
2000 \\
2000 \\
2000\end{array}$ & $\begin{array}{l}850 \\
850 \\
850 \\
850 \\
850 \\
850\end{array}$ & $\begin{array}{l}250 \\
250 \\
250 \\
250 \\
250 \\
250\end{array}$ & $\begin{array}{l}300 \\
300 \\
300 \\
300 \\
300 \\
300\end{array}$ & $\begin{array}{l}300 \\
300 \\
300 \\
300 \\
300 \\
300\end{array}$ & $\begin{array}{l}300 \\
275 \\
250 \\
225 \\
200 \\
175\end{array}$ & $\begin{array}{l}263 \\
238 \\
213 \\
188 \\
163 \\
138\end{array}$ & $\begin{array}{l}1200 \\
1200 \\
1200 \\
1200 \\
1200 \\
1200\end{array}$ & $\begin{array}{l}0 \cdot 009 \\
0 \cdot 010 \\
0 \cdot 012 \\
0 \cdot 013 \\
0 \cdot 015 \\
0 \cdot 018\end{array}$ & $\begin{array}{l}44 \\
45 \\
46 \\
40 \\
44 \\
42\end{array}$ & $\begin{array}{l}535 \\
535 \\
535 \\
535 \\
535 \\
535\end{array}$ & $\begin{array}{l}0 \\
0 \\
0 \\
0 \\
0 \\
0\end{array}$ & $\begin{array}{r}600 \\
300 \\
0 \\
600 \\
300 \\
0\end{array}$ & $\begin{array}{l}253 \\
242 \\
193 \\
216 \\
182 \\
150\end{array}$ & $\begin{array}{l}1 \cdot 05 \\
0 \cdot 98 \\
0 \cdot 99 \\
0 \cdot 85 \\
0 \cdot 90 \\
0 \cdot 87\end{array}$ & $\begin{array}{l}1 \cdot 03 \\
0 \cdot 98 \\
0 \cdot 99 \\
0 \cdot 82 \\
0 \cdot 86 \\
0 \cdot 82\end{array}$ \\
\hline \multicolumn{16}{|l|}{ Mean $\mu$} & $0 \cdot 95$ & $0 \cdot 87$ \\
\hline \multicolumn{16}{|l|}{ Standard deviation $\sigma$} & 0.07 & $0 \cdot 10$ \\
\hline$\sigma / \mu$ & & & & & & & & & & & & & & & & 0.08 & $0 \cdot 12$ \\
\hline
\end{tabular}


force in the inner column reinforcement, which can lead to premature hinging of the upper column.

\section{Comparison with other test results}

The model has been used to predict the joint shear strength of specimens without joint stirrups tested by Scott and Hamil, ${ }^{12}$ Kordina, ${ }^{13}$ Wilson ${ }^{14}$ and Parker and Bullman $^{15}$ (slab edge-column specimens). Data from slab edge-column tests by Parker and Bullman ${ }^{15}$ (see Table 1) and others ${ }^{16-17}$ (see Vollum and Newman ${ }^{8}$ for details) are included because data are not available for beam-column joints with $h_{\mathrm{b}} / h_{\mathrm{c}}$ below 1 . The slab edge-column tests give lower bounds to the joint shear strength because (a) Parker and Bullman's tests were stopped before failure and $(b)$ in the other tests, failure was attributed to moment transfer or punching shear. Details of the specimens and the results of the analysis are given in Table 1. Fig. 3 compares the predicted influence of joint aspect ratio $h_{\mathrm{b}} / h_{\mathrm{c}}$ on the joint shear strength of a specimen similar to Ortiz's specimen BCJ6 with test data. The joint aspect ratio was varied between 0.6 and 2 in the analysis by adjusting the column depth while maintaining the area of longitudinal reinforcement in the column at $3 \%$ of its crosssectional area. Fig. 3 shows that $(a)$ the model gives good estimates of joint shear strength and $(b)$ the influence of joint aspect ratio on joint shear strength is predicted safely.

\section{Strut and tie model for beam-column joints with stirrups}

The first author has carried out an extensive survey ${ }^{5,8}$ of test data ${ }^{6,7,9-13}$ to determine the influence of stirrups on joint shear strength. Joint stirrups were found to be effective if placed between the underside of the main reinforcement and the top of the compressive stress block in the beam (assumed to be of depth $0 \cdot 375 h_{\mathrm{b}}$ ). The results are given in Fig. 4 , which shows that joint shear strength is increased by joint stirrups but the increase in strength can be less than the yield capacity of the effective joint stirrups, as is commonly assumed. $^{6,9,10}$ The evidence is even more convincing for beam-column joints with $U$ bars in the beam. ${ }^{8}$ Fig. 4 indicates that the joint shear strength is given by the greater of $V_{\mathrm{c}}$ and

$$
V_{\mathrm{j}}=\left(V_{\mathrm{c}}-\alpha b_{\mathrm{e}} h_{\mathrm{c}} \sqrt{ } f_{\mathrm{c}}^{\prime}\right)+A_{\mathrm{sj}} f_{\mathrm{y}}
$$

where $V_{\mathrm{c}}$ is the joint shear strength without stirrups, $A_{\mathrm{sj}}$ is the effective area of joint stirrups, $f_{\mathrm{y}}$ is the yield strength of the stirrups and $\alpha$ is an efficiency factor which depends on factors including the column load, the concrete strength, $A_{\mathrm{sj}} f_{\mathrm{y}}$, the position of the stirrups and the joint aspect ratio. Analysis of test data suggests that a reasonable estimate for $\alpha$ is $0 \cdot 2$ rather than 0 as is commonly assumed ${ }^{6,9,10}$ (see Fig. 4).

The first author ${ }^{5,8,19}$ has previously demonstrated the shortcomings of existing methods for determining the design joint stirrup force and proposed ${ }^{8,19}$ a novel strut and tie model for external beam-column joints with stirrups which incorporates a stiffness analysis. This paper extends the brief outline of the method given previously. ${ }^{19}$ The model is an improvement on existing methods since it automatically takes into account the variation in the efficiency factor $\alpha$ (see equation (8)) by using a stiffness analysis to find the shear force resisted by the direct strut. Joint failure is assumed to occur because of either yielding of stirrups or concrete failure prior to yielding of stirrups. The layout of the model is shown in Figs 5 and 6. The centre line of the struts is defined at each node by the intersection of the lines of action of the appropriate components of the joint shear force (see Fig. 5). The horizontal eccentricity of the indirect struts at the nodes is dependent on the stress distribution assumed in the columns. For example, the horizontal eccentricity $e_{\mathrm{ib}}$ of the indirect strut at the bottom node (see Fig. 5) is given by

$$
e_{\mathrm{ib}}=x_{\mathrm{b}}-0 \cdot 5 x_{\mathrm{ib}}
$$

where $F_{\text {vib }}$ is the vertical component of the force in the lower indirect strut, $x_{\mathrm{b}}$ is the width of the stress block in the lower column (see Fig. 5) and

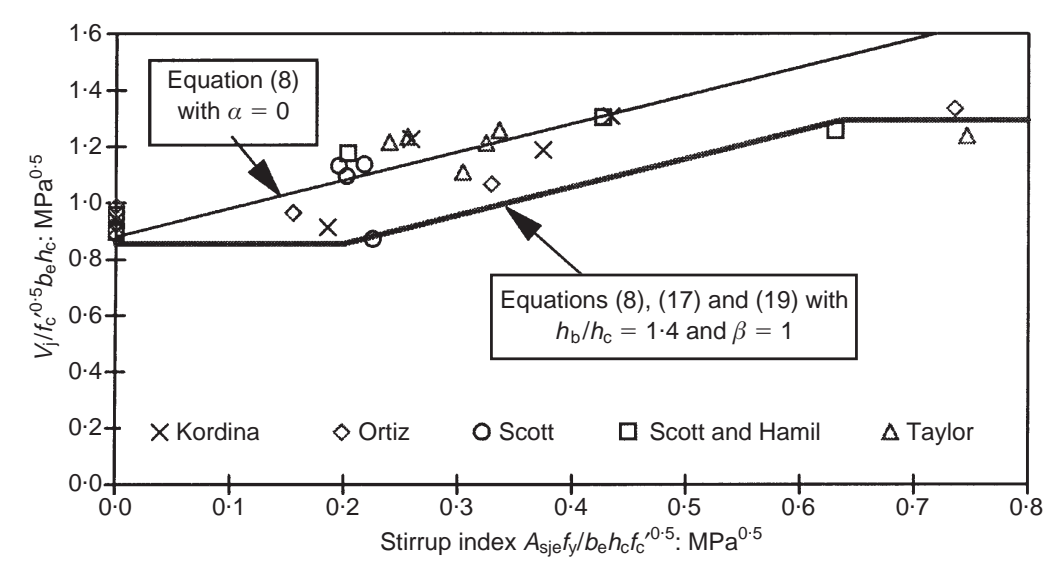

Fig. 4. Influence of stirrups on joint shear strength 


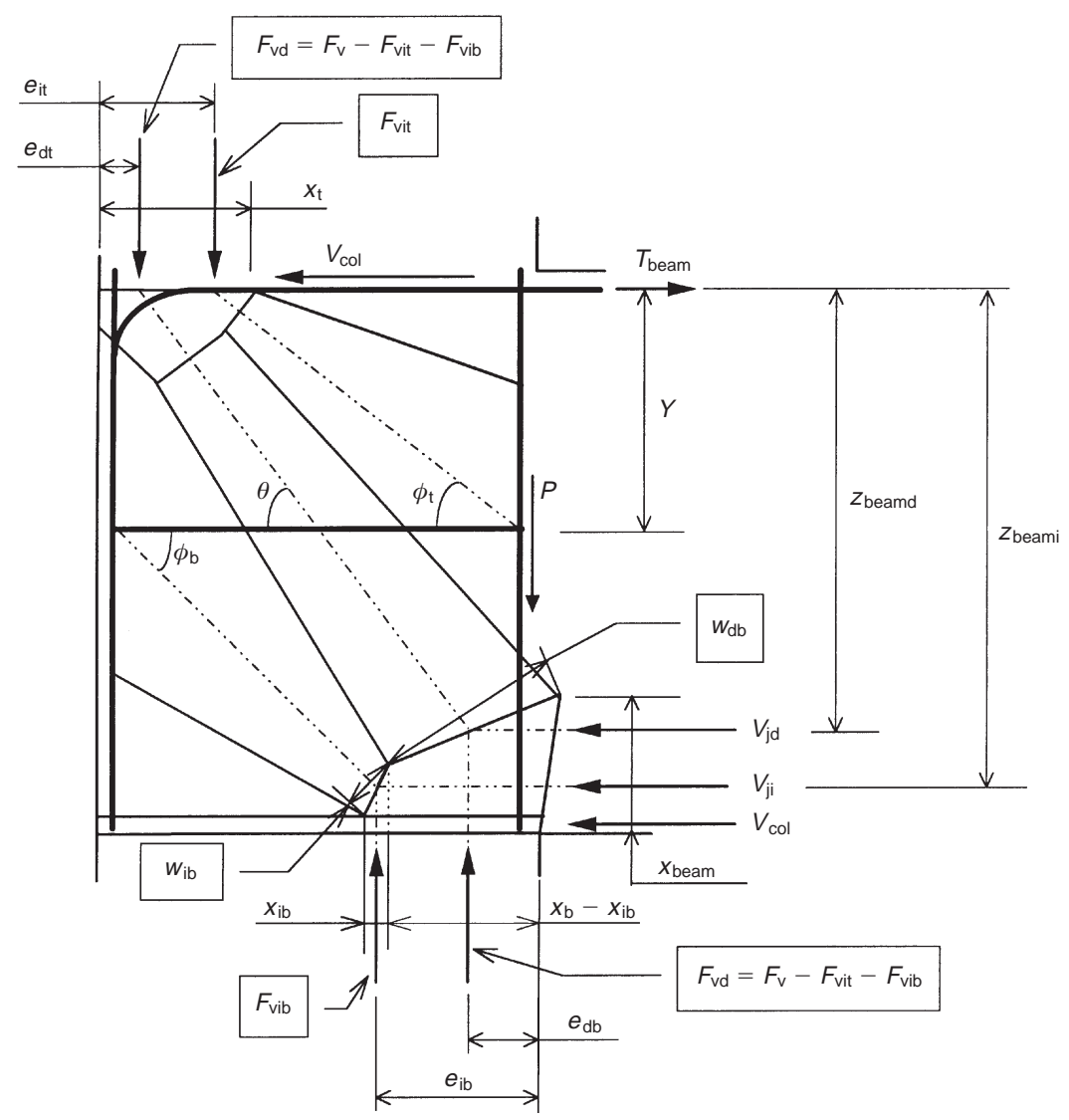

Fig. 5. Strut and tie model for beam-column joint with stirrups

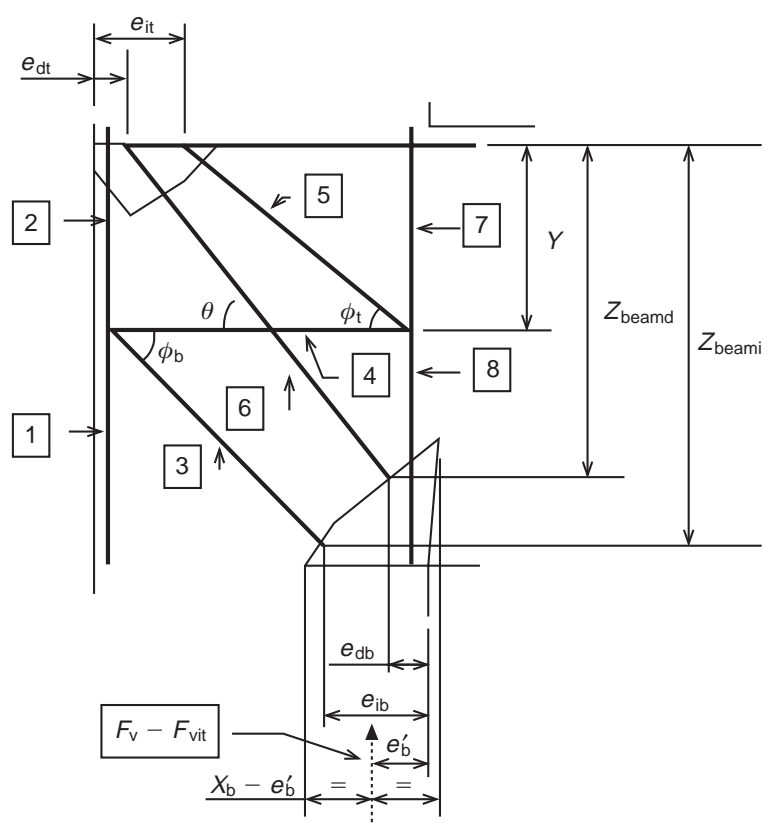

Fig. 6. Idealization of strut and tie model for stiffness analysis

$$
x_{\mathrm{ib}}=F_{\mathrm{vib}} / b_{\mathrm{e}} \sigma^{*}
$$

where $\sigma^{*}$ depends on the stress distribution assumed in the column; $\sigma^{*}$ is taken as

$$
\sigma^{*}=0 \cdot 5\left(F_{\mathrm{v}}-F_{\mathrm{vit}}\right) / b_{\mathrm{e}}\left(x_{\mathrm{b}}-e_{\mathrm{b}}^{\prime}\right)
$$

where $F_{\text {vit }}$ is the vertical component of the force in the upper indirect strut and $e_{\mathrm{b}}^{\prime}$ is the eccentricity of $\left(F_{\mathrm{v}}-F_{\text {vit }}\right)$ (see Fig. 6) at the bottom node. Equation (11) is based on the assumption that the resultant force in the column reinforcement is shared between the direct and indirect struts. The alternative assumption of using a stepped stress block is considered unnecessarily complex. A similar approach is used to derive the eccentricity of the upper indirect strut $e_{i t}$. The main difference is that the stress in each strut is assumed to be equal at the top node. Therefore, the node boundaries are orthogonal to the centre lines of the struts.

The member forces (in terms of the stirrup force $x$ ) and lengths adopted in the stiffness analysis are given in Table 2, which should be read in conjunction with Fig. 6. The model is calibrated by assuming effective strut widths at the nodes. The effective strut widths depend on the assumed concrete strength and are assumed to vary linearly between the ends of the struts. In reality, the concrete strength varies along each strut owing to variations in the multiaxial stress state but, to simplify matters, a notional concrete strength is adopted for each strut (i.e. $f_{\mathrm{d}}, f_{\text {it }}, f_{\text {ib }}$ ) on the basis of the inclination of its centre line and the mean stirrup strain. As previously discussed, the strut widths depend on the widths of the stress blocks at the joint boundaries (see Fig. 5), which in turn depend on the column 
Table 2. Member lengths and forces (see Fig. 6 for notation)

\begin{tabular}{l|c|c|c}
\hline Member & Length & Resultant force & $\begin{array}{c}\text { Force due to unit } \\
\text { biaction at ends } \\
\text { of member } 4\end{array}$ \\
\hline 1 & $d_{\text {beam }}-Y$ & $T_{\text {se }}$ & 0 \\
2 & $Y$ & $T_{\mathrm{se}}-X \tan \phi_{\mathrm{b}}$ & $-\tan \phi_{\mathrm{b}}$ \\
3 & $\left(Z_{\text {beami }}-Y\right) / \sin \phi_{\mathrm{b}}$ & $-X / \cos \phi_{\mathrm{b}}$ & $-1 / \cos \phi_{\mathrm{b}}$ \\
4 & $h_{\mathrm{c}}-2 d^{\prime}$ & $X$ & 1 \\
5 & $Y / \sin \phi_{\mathrm{t}}$ & $-X / \cos \phi_{\mathrm{t}}$ & $-1 / \cos \phi_{\mathrm{t}}$ \\
6 & $Z_{\text {beamd }} / \sin \theta$ & $\left(-V_{\mathrm{j}}+X\right) / \cos \theta$ & $1 / \cos \theta$ \\
7 & $Y$ & $T_{\mathrm{si}}^{*}$ & 0 \\
8 & $Z_{\text {beamd }}-Y$ & $T_{\mathrm{si}}^{*}-X \tan \phi_{\mathrm{t}}$ & $-\tan \phi_{\mathrm{t}}$ \\
\hline
\end{tabular}

bar forces, which are indeterminate. To simplify matters, the column bar forces are not adjusted to match the widths of the concrete stress blocks at the joint boundaries to the assumed effective strut widths, as shown in Fig. 5. This has been justified by Vollum, ${ }^{5}$ who showed that the predicted joint strength is relatively insensitive to adjustments to the column bar forces. The strain in the direct and indirect struts is assumed to be -0.002 at the top node at joint failure, on the basis that the concrete fails. This is achieved by selected effective strut widths (at the top node) to make the stresses in both struts equal the notional concrete strength in the direct strut $f_{\mathrm{d}}$. The strain in the indirect struts is taken as -0.002 if the stress is greater than its notional concrete strength, $f_{\text {it }}$ or $f_{\text {ib }}$ as appropriate. The effective width of the direct strut at the bottom node is taken as

$$
w_{\mathrm{db}}^{*}=C h_{\mathrm{c}} / \sin \theta
$$

where the coefficient $C$ is derived from analysis of test data. The effective width of the indirect strut (normal to its axis) at the bottom node $w_{\mathrm{ib}}^{*}$ is taken as the greater of $w_{\mathrm{ib}}$ and

$$
w_{\mathrm{ib}}^{*}=w_{\mathrm{ib}}\left(w_{\mathrm{db}}^{*} / w_{\mathrm{db}}\right)
$$

where $w_{\mathrm{db}}$ and $w_{\mathrm{ib}}$ are related to the widths of the concrete stress blocks in the beam and the lower column as shown in Fig. 5. The effective width of the indirect struts at the intersection with the column bars is taken as the lesser of $2 Y \cos \phi$ and $2\left(d_{\mathrm{b}}-X_{\text {beam }}-Y\right) \cos \phi$.

The stirrup force is calculated by virtual work in an analysis that considers deformations within the joint. The extension of each strut is found by dividing it into ten elements of equal length and summing the extensions of each element. The extensions are calculated in terms of the strain at the centre of each element, which is derived from the appropriate stress using equation (3). The force in the direct strut is limited to

$$
D=1.01 b_{\mathrm{e}} w_{\mathrm{db}}^{*} f_{\mathrm{d}}
$$

It is assumed that increments in shear force are resisted by the indirect struts if the force in the direct strut equals $D$. Shear force is transferred to the indirect struts by increasing the strain in the direct strut by increasing $n$ in equation (15) if $\sigma_{i} / f_{\mathrm{d}}>1$ :

$$
\varepsilon_{\mathrm{d} i}=-0.002\left(\sigma_{i} / f_{\mathrm{d}}\right)^{n}
$$

where $n \geqslant 1, \varepsilon_{\mathrm{d} i}$ is the strain in element $i$ of the direct strut and $\sigma_{i}$ is the stress in element $i$ of the direct strut.

Theoretically, the maximum possible joint shear strength corresponds to the development of a uniform inclined stress field and (assuming the effective depth for shear is $0.9 d_{\mathrm{c}}$ ) is given by

$$
V_{\text {jmax }}=0 \cdot 9 b_{\mathrm{e}} d_{\mathrm{c}} f_{\mathrm{d}} \sin \theta \cos \theta
$$

Analysis $^{5,8}$ of test data ${ }^{6,7,9-13}$ indicates that equation (16) progressively overestimates the joint shear strength as $f_{\mathrm{c}}^{\prime}$ increases, and that a better estimate of the maximum possible joint shear strength is given by

$$
\begin{aligned}
V_{\mathrm{j}} & <0.97 b_{\mathrm{e}} h_{\mathrm{c}} \sqrt{ } f_{\mathrm{c}}^{\prime}\left[1+0.555\left(2-h_{\mathrm{b}} / h_{\mathrm{c}}\right)\right] \\
& <1.33 b_{\mathrm{e}} h_{\mathrm{c}} \sqrt{ } f_{\mathrm{c}}^{\prime}
\end{aligned}
$$

The reduction in maximum joint shear strength with joint aspect ratio is speculative.

\section{Application of model to test data}

The following assumptions are made in the analysis.

(a) Stirrups are considered effective if placed within the top five-eighths of the beam depth below the main beam reinforcement.

(b) The stirrup force is assumed to act at the centroid of the effective stirrups.

(c) $T_{\mathrm{si}}^{*}$ is taken as $1 \cdot 15 T_{\mathrm{si}}$ unless flexural failure of the upper column is imminent. In this case, the multiplication factor $K$ is taken as the greater of $1 \cdot 15$ and the factor required to reduce the stress at the top node to $f_{\mathrm{d}}$.

(d) The failure load is calculated at either $N_{\text {crit }}$ (where $N_{\text {crit }}$ is the column load at which the predicted joint shear strength is a maximum) or the actual column load if this is less than $N_{\text {crit }}$.

(e) Failure is assumed to occur owing to either yielding of the stirrups or concrete failure prior to yielding of stirrups. If the stirrups yield, the failure load is maximized by varying the strain in the stirrups. Equation (17) is used to calculate the maximum possible joint shear strength. If the 'stirrup index' $A_{\mathrm{sj}} f_{\mathrm{y}} /\left(b_{\mathrm{e}} h_{\mathrm{c}} \sqrt{ } f_{\mathrm{c}}^{\prime}\right)$ is less than $S I_{\text {min }}$ (where $S I_{\text {min }}$ is typically less than $0 \cdot 2$ ), the resulting failure load is less than that predicted neglecting the joint stirrups (using the model for joints without stirrups). In this case, the joint strength is not increased by the stirrups and the failure load is taken as that without stirrups. $S I_{\min }$ corresponds to $\alpha$ in equation (8) and depends on factors including joint aspect ratio, concrete strength and column load.

The model was calibrated for Ortiz's specimens, with $C=0.349$ in equation (12). Various parametric studies 
were then carried out. The predicted joint shear strength was found to increase as the column load was increased from zero to a critical value $N_{\text {crit }}$. The increase in joint strength ranges from less than $3 \%$ for $h_{\mathrm{b}} / h_{\mathrm{c}}=1$ to about $15 \%$ for $h_{\mathrm{b}} / h_{\mathrm{c}}=2$. The predicted increase in joint strength is small enough to be consistent with the earlier conclusion that joint strength is reasonably independent of column load unless a hinge forms in the upper column. The predicted joint strength reduces if $N$ is increased above $N_{\text {crit }}$ because the width of the direct strut is limited by equation (12). In practice, the test data provide no evidence that joint strength reduces as the column load is increased. This implies that the width of the direct strut increases as $N$ is increased above $N_{\text {crit }}$. The solution procedure avoids this difficulty by calculating the failure load at $N_{\text {crit }}$ if $N$ is greater.

The model has been used to predict the failure load of specimens, including those in Table 1, with $C=0 \cdot 349$. Results are given in Table 1 , the ratio of the predicted and actual failure loads $P_{\text {pred }} / P_{\text {test }}$ is plotted against the stirrup index $A_{\mathrm{sj}} f_{\mathrm{y}} /\left(b_{\mathrm{e}} h_{\mathrm{c}} \sqrt{ } f_{\mathrm{c}}^{\prime}\right)$ in Fig. 7 and statistics of the analysis are given in Table 1 .

\section{Comparison with other design methods}

Previously, the authors have proposed a simple method for the design of beam-column joints based on equation (8). ${ }^{8}$ Elsewhere, it has been shown ${ }^{5,8}$ that the authors' simple design method $^{8}$ gives more realistic estimates of joint strength than other methods, ${ }^{6,9,10,20}$ including codes. ${ }^{21,22}$ The authors ${ }^{8}$ take joint shear strength as the lesser of $V_{\mathrm{c}}$ and $V_{\mathrm{j}}$ given by equation (8), where $\alpha$ is conservatively taken as 0.2 and $V_{\mathrm{c}}$ is the joint shear strength without stirrups, which is taken as

$$
V_{\mathrm{c}}=0.642 \beta\left[1+0.555\left(2-h_{\mathrm{b}} / h_{\mathrm{c}}\right)\right] b_{\mathrm{e}} h_{\mathrm{c}} \sqrt{ } f_{\mathrm{c}}
$$

where $\beta=1.0$ for connections with $\mathrm{L}$ bars and 0.9 for connections with $\mathrm{U}$ bars.
Equation (18) was calibrated using joint shear forces calculated assuming that the shear force in the beam is transferred directly into the centroid of the outer layer of column bars (see Fig. 2). The rectangular-parabolic stress block ${ }^{19}$ of Eurocode 2 was used in the section analysis, with a maximum possible concrete stress of $f_{\mathrm{c}}^{\prime}$. The maximum joint shear strength was limited by equation (17). Failure loads have been calculated for the specimens in Table 1 using the authors ${ }^{, 5,8}$ simple design method. Results are given in Table 1 and the ratio $P_{\text {pred }} / P_{\text {test }}$ is plotted against the stirrup index $A_{\mathrm{sj}} f_{\mathrm{y}} /\left(b_{\mathrm{e}} h_{\mathrm{c}} \sqrt{ } f_{\mathrm{c}}^{\prime}\right)$ in Fig. 8. Comparison of Figs 7 and 8 shows that the strut and tie model is more accurate than the simplified method owing to reduced scatter. This is confirmed by the statistics in Table 1 . The reason for the improved accuracy of the strut and tie model is that it takes into account the variation in $\alpha$ (see equation (7)) with the joint aspect ratio, the column axial load, $A_{\mathrm{sj}} f_{\mathrm{y}}$, the stirrup position and the concrete strength.

\section{Conclusions}

Strut and tie modelling is widely advocated for the design of non-uniform regions such as short-span beams and beam-column joints. The analysis and design of beam-column joints with strut and tie models are complex owing to difficulties in determining node dimensions and the proportion of joint shear force resisted by the stirrups. In the current work, strut dimensions have been established empirically from a back analysis of selected test results and the validity of the resulting model has been demonstrated by analysing other test data. Models have been developed for joints with and without stirrups. Test data have been used to show that it is unsafe to assume that the increase in joint strength provided by stirrup equals their yield capacity. Therefore, a stiffness-based approach is required to determine the shear force resisted by the direct strut if joint stirrups are provided. The resulting strut and tie model predicts joint shear strength more

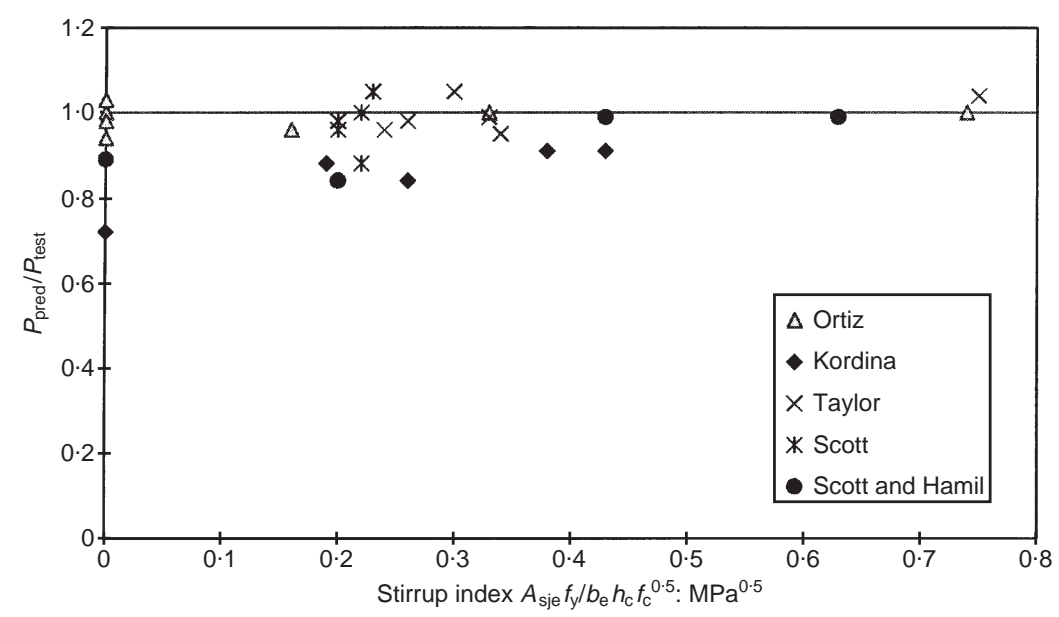

Fig. 7. Influence of stirrup index on $P_{\text {pred }} / P_{\text {test }}$ for strut and tie model 


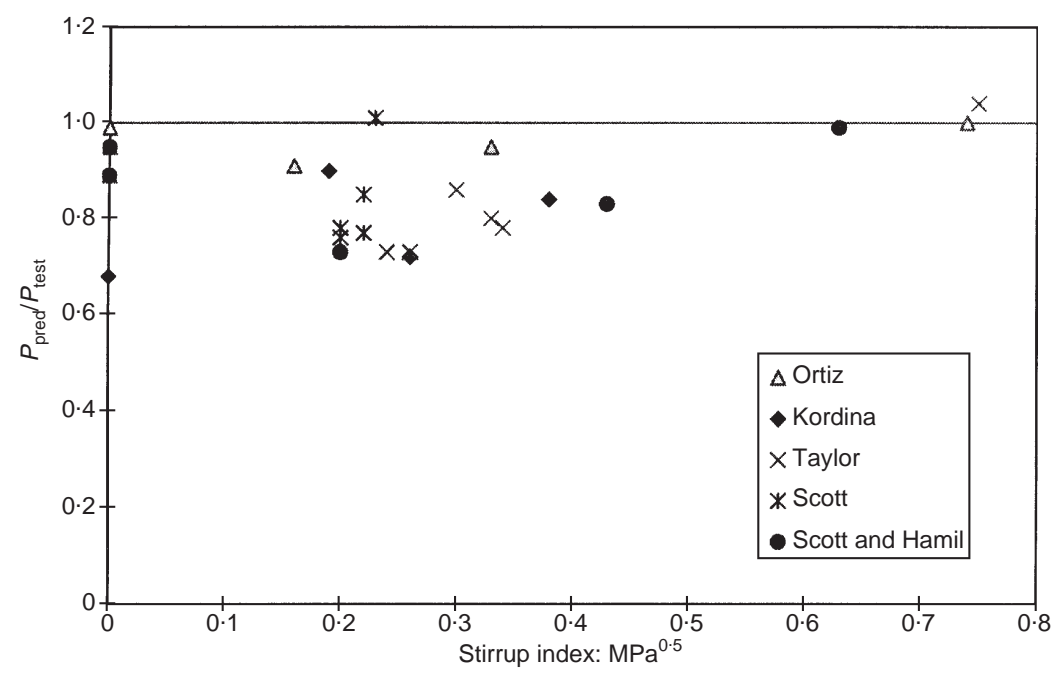

Fig. 8. Influence of stirrup index on $P_{\text {pred }} / P_{\text {test }}$ for simplified design method ${ }^{8}$

reliably than existing non-finite-element methods (of which the authors' simplified method ${ }^{8}$ is considered the most realistic) and some finite-element techniques. ${ }^{5}$ The strut and tie model is necessarily complex but can be incorporated into spreadsheet-based design techniques. In the light of this work, the authors believe that the behaviour of beam-column joints is too complex to be adequately represented by simple strut and tie models based on plasticity theory. Furthermore, the authors believe that this conclusion can be extended to other structures such as deep beams, corbels and shear walls when shear transfer is by way of a direct strut and indirect struts that are equilibrated by stirrups. Assuming the stirrups yield, the main difficulty is to estimate the contribution of the direct strut since it is statically indeterminate. It is clearly simplest (and permissable in terms of the lower-bound theorem of plasticity), but in general unrealistic, to neglect the contribution of either the direct strut or the stirrups. Other approaches to this problem, and their shortcomings, have been discussed by the first author. ${ }^{19}$ The difficulties faced in determining the contribution of the direct strut are of significance since strut and tie modelling is claimed ${ }^{1-4}$ to provide a simple, logical and realistic approach to the design of complex structures. Despite this, the authors believe that classical strut and tie modelling based on plasticity theory ${ }^{3}$ is a useful design tool. If a simple design method is required for external beam-column joints, the authors recommend their simplified method. ${ }^{8}$

\section{References}

1. Collins M. P. and Mitchell D. Prestressed Concrete Structures. Prentice-Hall, Englewood Cliffs, 1991.

2. Schlaich J., Jennewein M. and Schafer K. Towards a con- sistent design of structural concrete. PCI Journal, 1987, 32, 74-150.

3. MARTi P. A simple, consistent approach to structural concrete. The Structural Engineer, 1999, 77, No. 9, 20-28.

4. Comité Euro-International dU Béton and Federation International de la Precontrainte. Model Code for Concrete Structures. CEB-FIP International Recommendations, 1990. Thomas Telford, London, 1993.

5. Vollum R. L. Design and Analysis of Beam-Column Joints. $\mathrm{PhD}$ thesis, University of London, 1998.

6. Reys de Ortiz I. Strut and Tie Modelling of Reinforced Concrete Short Beams and Beam-Column Joints. PhD thesis, University of Westminster, 1993.

7. ScOtT R. H. The effects of detailing on RC beam/column connection behaviour. The Structural Engineer, 1992, 70, No. 18, 318-324.

8. Vollum R. L. and Newman J. B. The design of reinforced concrete external beam-column joints. The Structural Engineer, in press.

9. Parker D. E. and Bullman P. J. M. Shear strength within reinforced concrete beam-column joints. The Structural Engineer, 1997, 75, No. 4, 53-57.

10. Sarsam K. F. and Phipps M. E. The shear design of in-situ reinforced beam-column joints subjected to monotonic loading. Magazine of Concrete Research, 1985, 37, No. 130, 16-28.

11. TAYLOR H. P. J. The Behaviour of In-situ Concrete Beam-Column Joints. Cement and Concrete Association, Wexham Springs, 1974, Technical Report 42.492.

12. Scott R. H. and Hamil S. J. Personal communications, 1997.

13. Kordina K. Bewehrungsfuhrung in Ecken und Rahmenendknoten. Deutscher Ausschuss fur Stahlbeton, 1984, Part 354.

14. WILSON I. D. SIFCON joints in pre-cast concrete structures. Proceedings of the 8th BCA Annual Conference on Higher Education and the Concrete Industry, Southampton, 1998, 227-239.

15. Parker D. E. and Bullman P. J. M. Edge-column connections in flat slab construction. The Structural Engineer, 1998, 76, No. $13,253-256$.

16. Moenle J. Strength of slab-column edge connections. ACI Structural Journal, 1988, 85, 89-98.

17. Luo Y. H. and Durrani A. J. Equivalent beam model for flatslab buildings - part II: exterior connections. ACI Structural Journal, 1995, 92, 250-257.

18. British Standards Institution. Design of Concrete Structures: Part 1: General Rules and Rules for Buildings. BSI, Milton Keynes, 1992, Eurocode 2.

Magazine of Concrete Research, 1999, 51, No. 6 
19. Vollum R. L. Strut and tie modelling of external beam-column joints. FIB Symposium. Prague, 1999.

20. Scott R. H., Feltham I. and Whittle R. T. Reinforced concrete beam-column connections and BS 8110. The Structural Engineer, 1994, 72, No. 4, 55-60.

21. British Standards Institution. Design Provisions for Earthquake Resistance of Structures. BSI, Milton Keynes, 1995, Eurocode 8 .
22. ACI-ASCE Committee 352R-91. Recommendations for the Design of Beam-Column Joints in Monolithic Reinforced Concrete Structures. American Concrete Institute, Detroit, 1998, ACI Manual of Concrete Practice, Part 3.

Discussion contributions on this paper should reach the editor by 31 May 2000 